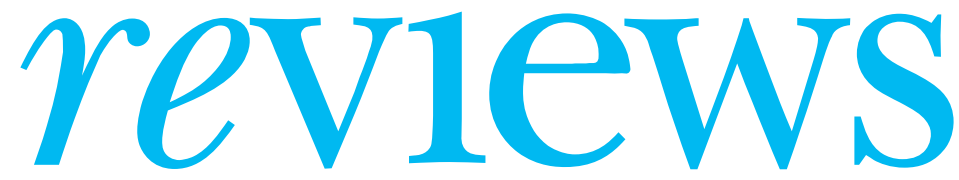

BOOKS • CD ROMS • ART •WEBSITES $\bullet$ MEDIA $\bullet$ PERSONAL VIEWS $\bullet$ SOUNDINGS

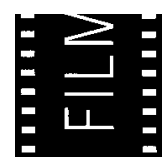

\section{Munnabhai M.B.B.S.}

Directed by Rajkumar Hirani On general release in India Check locally for release dates elsewhere

\section{Rating: $\star \star \star$}

$\mathrm{B}$ ollywood (India's version of Hollywood, based in Mumbai) makes about 200 movies annually. Doctors in these movies are usually saints and most manage complex medical procedures, such as cardiac surgery in outpatient departments, and diagnose pregnancy by feeling

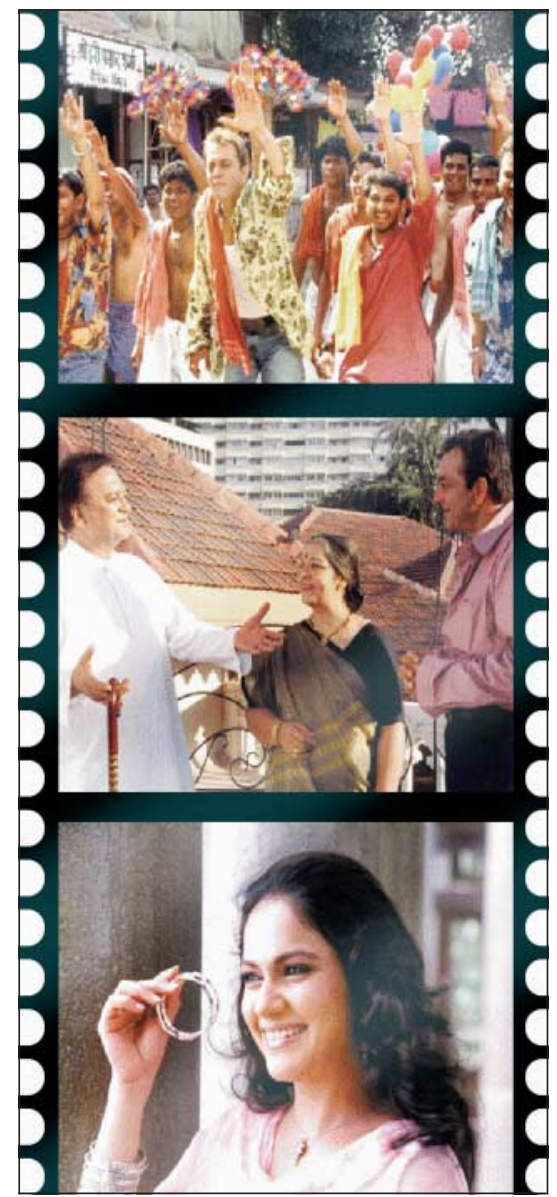

Be more humane, the film urges doctors the pulse. So a Hindi movie that uses correct medical terminology and real locations-I recognised the anatomy lecture hall of my medical school and cannot express the warm feeling that came over me-is bound to stand out. That this movie also has its audiences splitting their sides makes it unique.

The plot is simple: an underworld don and hoodlum pretends that he is a doctor running a charitable clinic in the city to please his parents who live in a village. When the truth gets out, his parents are shattered. The only way that he can atone for his sins is by becoming a doctor. To do this, he needs to enter medical college and pass his exams. Readers will need to see the film to find out whether or not he succeeds.

Many of the one liners are most likely to be best understood by those with a Mumbai background. And doctors will appreciate the black humour better than others. But all viewers are likely to find the film hilarious, as well as well acted. This month Sunjay Dutt, who plays Munnabhai, won India's equivalent of the best actor Oscar.

Beneath the surface humour there is a hidden-or perhaps not so hiddenmessage throughout. As if inspired by Patch Adams, the Robin Williams film about a doctor who believes in laughter as the best medicine, Munnabhai M.B.B.S. exhorts doctors to be more humane towards patients. There are references to senior staff regarding patients as exhibits, which is most humiliating for patients as I know from my own experience as a patient when a classmate saw me purely as an "interesting case.” While some scenes stretch credibilityfor example, when the medical school dean (played marvellously by Boman Irani) states that empathy is unnecessary and patients must be seen purely from a scientific perspective-surely we all know doctors who could do with a little more humanity.

Some of the funny episodes are based on real life incidents-which, of course, are not that funny but instead rather worrying. For example, Munnabhai uses his cellular phone (among other creative methods) to cheat in examinations. Such activity has been reported in India recently. There is also a scene where gangsters enter the hospital in the middle of the night, which is obviously based on an incident that took place about 10 years ago. There is also a takeoff of laughter therapy as an alternative medicine.

As one who firmly believes that physicians must read outside their profession to become better doctors, I found myself

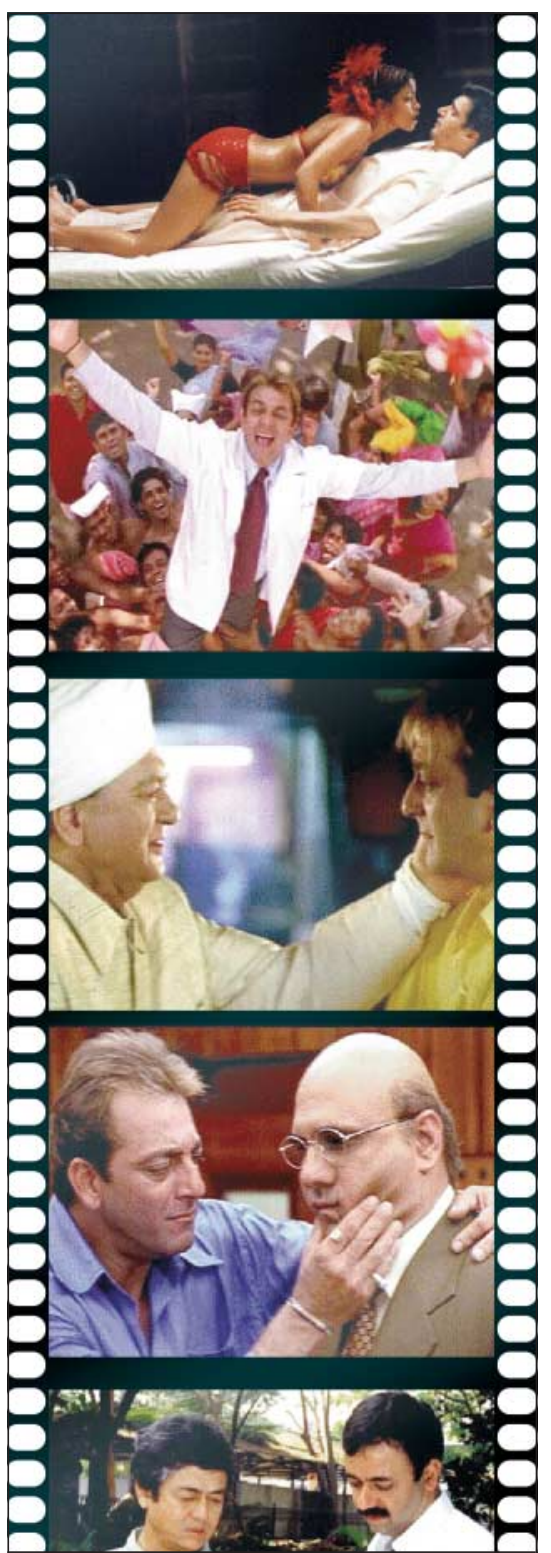

strongly recommending Munnabhai M.B.B.S. to all my colleagues. They will find it a riot and some will perhaps reflect on it.

The producer seems to have recognised that he has found a winning formula, and we now hear that Munnabhai LLB is apparently in the pipeline. Having seen that laughter is the best medicine, will we now learn that the law's an ass?

Sanjai Pai consultant pathologist, Manipal Hospital, Bangalore, India

spai@bgl.vsnl.net.in 


\section{SOUNDINGS \\ Evidence based medicine}

If the evidence based approach were applied to all our activities, medical care would improve immensely, but new difficulties would arise.

We would see the greatest improvement in the large body of habits surrounding medical practice: the routines and rituals. There is no evidence that people recovering from abdominal surgery should firstly be offered sips, then glasses of water, and then clear fluids followed by soups, soft diet, light diet, and so on. There is no evidence for the need to dress clean wounds; nor is there evidence for the usefulness of sealing sprays. Giving hospital patients laxatives and sedatives cries out for scientific scrutiny, to prove that their routine use is not harmful.

These are the little things that matter. Many of them are practised without any thought to need, cost, nuisance, and more serious consequences.

In the middle field are the standard treatments and procedures. There has been much effort to obtain evidence for the validity of the mainstream therapies, which is, without doubt, a salutary development. However, there is a recognisable tendency by the elite large teaching institutions to evolve sophisticated "gold standards" and "state of the art" therapies. They forget that hospitals and clinics in most parts of the world are far too austere to make use of leading edge technologies. The enthusiasts for revolutionary methods overlook the truth of the adage that the best is often the enemy of the good.

What the "best" treatment is will depend on the circumstances, and ignoring this simple fact can cause immense harm.

While the demand for evidence is rational and justified, difficulties may arise at the cutting edge, for how does one produce evidence for innovation? The much celebrated introduction of general anaesthesia would certainly be deemed unethical today, as would many of the pioneering discoveries in medical treatment and surgical procedures of the 19th and 20th century. The greats of medical progress would all be in court or in jail.

The great merit in the call for evidence is that medical practice might rid itself of quackery; the great danger is that innovation may be stifled. The quest for risk avoidance at all cost may well stall progress.

Imre Loefler editor, Nairobi Hospital Proceedings, Kenya

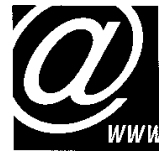

\section{Websites on South Asian health}

outh Asia has about a quarter of the world's population. Bangladesh has 1 the world's highest population density (other than microstates such as Singapore), and India alone, although it occupies only $2.4 \%$ of the world's land area, is home to about a sixth of the human race and recently became only the second country in the world to cross the one billion mark (www. indianchild.com/population of india.htm). Many of the people of South Asia live in and other resources relevant to health professionals.

Reproductive health and women's rights are important health issues in te region and the Global Reproductive Health Forum South Asia enables academics, scholars, and activists in these fields to disseminate their work to an international audience. Hosted by Harvard University in the United States, the site (www.hsph.harvard. edu/Organizations/healthnet/SAsia/) has in-depth modules on subjects such as domestic violence, dowry, violence against women, and injectable contraceptives.

Doctor NDTV (www.doctorndtv.com) is the site of an Indian daytime television show that is devoted exclusively to patient information. Aimed at the consumer, the site is bright, easy to browse, and is staffed by a large team of named experts in subjects from allergy and immunology through to urology. Each clinician's name is a

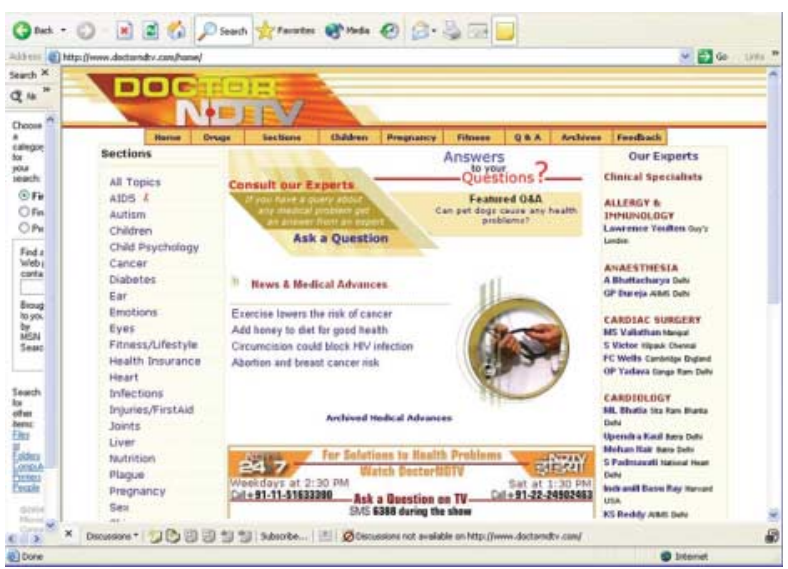

poverty and have limited access to facilitiesfresh, clean water, for example-that people take for granted in other parts of the world, such as Europe and the United States.

The South Asia Health Forum (www sahf.net) aims to promote health in the region by providing "a platform for the medical fraternity of South Asia to work closely in a spirit of empathy, trust and understanding." The forum defines South Asia as consisting of Afghanistan, Bangladesh, Bhutan, India, Maldives, Nepal, Pakistan, and Sri Lanka, and states, "Because our people have common problems we will be able to better work out effective solutions." The site provides evidence based information on specific disease conditions, including AIDS, infertility, and malaria; healthy lifestyle options; and patientoriented information taking into account the health needs of specific age and gender groups in the region.

In the same vein, the South Asia Public Health Forum (www.saphforg) provides a means of improving communication and interaction between health professionals either working in South Asia or health professionals with an interest in health in South Asia. The site offers a members' discussion forum and links to regularly updated news hypertext link to a page giving his or her career history. There is news about medical advances and an online opinion poll. One question this week was "should homosexuals be allowed to adopt children?"

One of the good things about the internet is that it can provide a public platform to those whose voices are not normally heard. In the spirit of this, Propoor (www.propoor.org) is a portal that meets the needs of non-profit organisations in South Asia. Set up in 1998, it says it is "committed to the dissemination of information and promotion of sustainable development initiatives, in response to the needs of under represented and marginalized sectors of society in South Asia."

Competing interests: guest editor Samiran Nundy is on the editorial board of www.sahf.net and is one of Doctor NDTV's gastrointesinal surgery experts. $B M J$ deputy editor Kamran Abbasi and guest editor Zulfiqar Bhutta are on the editorial board of www.sahf.net

Chibuzo Osdigwe fourth year medical student University of Calabar, Nigeria, and BMJ Clegg scholar

codigwe@bmj.com 


\section{Is cricket the magic glue that unites South Asia?}

$\mathrm{I}$

n South Asia, cricket has come to bear the promise of delivering lasting peace to a region tormented by a half century of strife. It may seem flippant to suggest that a sport will accomplish this when almost all else has failed, but consider the following. Mounting enmity between India and Pakistan is threatening to devour the entire region. Decades of failed diplomacy testify to the futility of conventional peace moves, and intransigent foreign policy positions bring the two neighbours ever closer to a nuclear flashpoint. India and Pakistan may speak the same language, but their deadlock cries out for a new medium of communication.

Like marmalade, tweed jackets, and other things English, cricket is an acquired taste, which makes it slow to pick up but impossible to let go of. Introduced to the subcontinent in the $1800 \mathrm{~s}$, by the $1920 \mathrm{~s}$ it was commanding great popularity in colonial India. In 1932 India became a Test playing country and, five years after the partition of 1947, Pakistan followed suit. In a cheerless, gloomy existence towards the bottom end of health and economic indices, the two nations found joy in cricket. It is easy to see why. Cricket provided a global forum for Pakistan and India to demonstrate talent and spirit, and defeat more advanced nations, such as England and Australia. Naturally enough, it cast a spell on the masses, became the embodiment of national self esteem, and turned cricket players into icons and celebrities.

\section{Cricket has suddenly acquired huge public health significance in South Asia}

A sport followed and played with equally fervent passion on both sides of the border has the power to be an instrument of peace, but it can also backfire, often quite unpredictably. For either country, a cricket loss to the neighbour can play havoc with national morale. Ruling party officials in India have expressed concern that a poor cricket showing in Pakistan might cost them the national election. In Pakistan, after India snapped cricket ties in the wake of the Kargil incursion of 1999, the mood turned sombre and national frustration began to crescendo. It is a testimony to the hold of cricket on the subcontinent that it took the restoration of cricketing links in the form of the 2003-4 series in Pakistan for the peoples of both countries to be finally convinced that the current thaw in relations was genuine.

Cricket's South Asian legions are not limited to India and Pakistan. In 1981 Sri

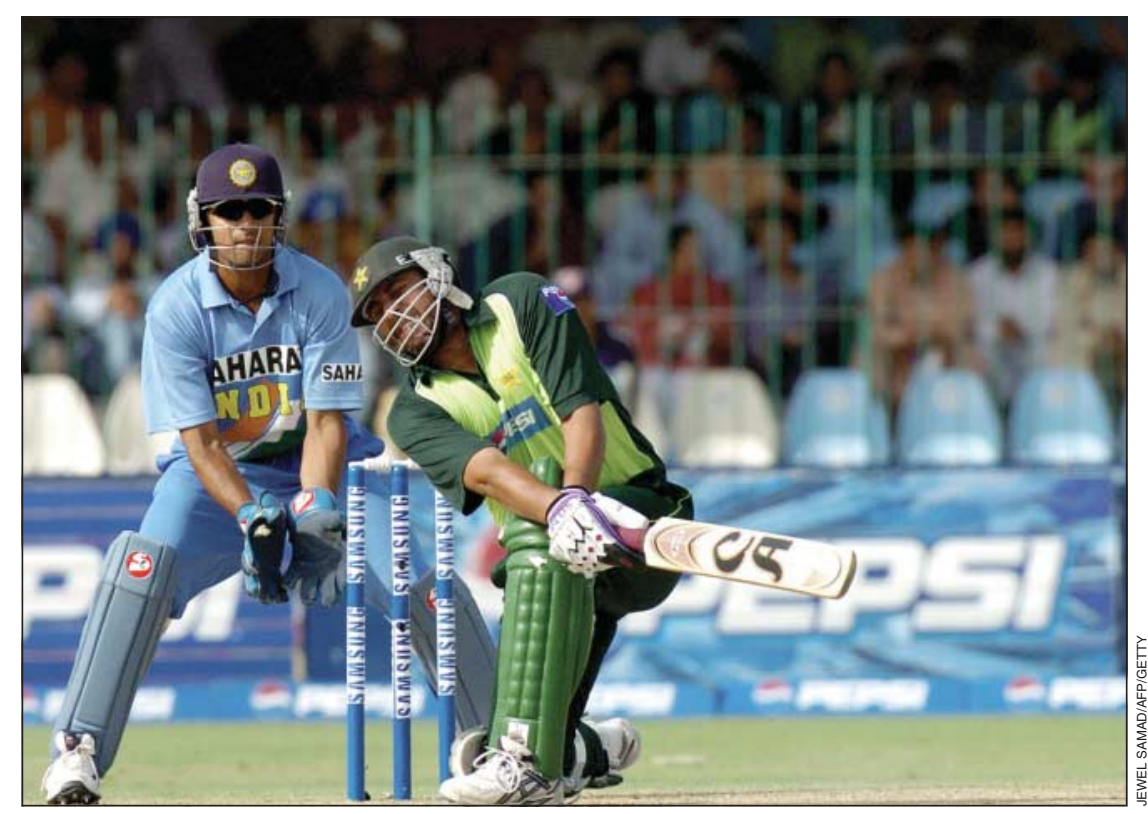

Can cricket serve peace? Inzamum-ul-Haq sweeps as Rahul Dravid watches. India are touring Pakistan after 14 years

Lanka became a Test playing country and, in 2000, so did Bangladesh. The sport has also made great strides in Nepal, which recently stunned South Africa with a shock defeat in the junior world cup.

Few other pastimes embody fair play and respect for law so completely. Cricket is emerging as the one universal language of South Asia that could be a foolproof basis for finding common ground in other areas of life.

With the power to promote peace and, therefore, the health and wellbeing of hundreds of millions, cricket has suddenly acquired huge public health significance in South Asia. But for cricket to heal the gaping wound between India and Pakistan, we're going to need lots of it. The homoeopathic doses administered thus far-a mere 12 Test series over 52 years during which sporting ties were suspended over half the time-simply will not do. Above all else, the mammoth South Asian fan base needs to start seeing cricket as a pursuit of shared enjoyment, not as a calculus of honour and shame. This is bound to happen as the two countries play each other more and more. No one understands this better than Indian and Pakistani cricketers themselves, who have always got along famously.

Recently, as if to answer sceptics who said that cricket cannot serve peace, India and Pakistan played a match in Karachi. A largely Pakistani crowd exceeding 30000 cheered the Indian team on to the field with a deafening roar. In 1987 Pakistani president Zia ul Haq had seized the diplomatic initiative by turning up at an India-Pakistan test match in Jaipur. This time in Karachi it was Priyanka Gandhi, Congress Party hope and heir-apparent to the Nehru dynasty, who made a splash that won her instant celebrity in Pakistan and may have wrongfooted India's ruling BJP. Even Colin Powell became a believer. "It's fascinating what sports can do," he was quoted as saying shortly afterwards.

\section{Cricket cannot solve the} conundrum of Kashmir. But it can bring both parties to the table

Of course, cricket cannot do everything It cannot, for example, solve the territorial conundrum of Kashmir that is at the heart of the India-Pakistan conflict. But cricket can bring both parties to the table. If negotiations stall, cricketspeak can restore the channels of communication. Can't agree on the Chenab formula or the fate of the valley? Why not take a break and discuss Sachin Tendulkar's poetic cover drives or Shoaib Akhtar's blinding yorkers?

The British have long said that cricket is the best of games. India and Pakistan now find themselves in a position to prove it beyond a shadow of doubt.

Saad Shafqat associate professor of neurology, Aga Khan University Hospital, Karachi, Pakistan

Nadir Bharucha professor of neurology, Bombay Hospital Institute of Medical Sciences, Mumbai, India 